\title{
Online Learning Readiness, Academic Resilience, and Subjective Well-Being of Junior High School Students during the COVID 19 Pandemic
}

\author{
Nadhila Safitri \\ Master of professional psychology, Islamic University of Indonesia, Indonesia \\ nadhila.ns@gmail.com \\ Sumedi P. Nugraha \\ Master of professional psychology, Islamic University of Indonesia, Indonesia \\ sumedi.nugraha@uii.ac.id \\ (corresponding author)
}

\begin{abstract}
Online learning process in COVID-19 pandemic can decline the quality of subjective well-being of students. The constraints faced by the students in doing the online learning can make them more frequently feel negative emotions such as being anxious, stressful, confused or bored. The aim of this study is to test the online learning readiness and academic resilience on the subjective well-being among students. A number of previous researches showed that the students ready to have online learning and having a good academic resilience could increase their subjective wellbeing. This study involved 200 students of Junior High School ' $X$ ' Lampung having online learning. It used three instruments: (a) scale of positive and negative experience (SPANE) (Diener, Wirtz, Tov, Kim-Prieto, Choi, Oishi, \& Biswas-Diener, 2009), (b) academic resilience scale (Martin \& Marsh, 2006), and (c) scale of student's e-learning readiness questionnaire (Aydin \& Tasci, 2005). The test of hypothesis used the Doubled Regression Analysis Technique (SPSS 20). The results of this study showed that the online learning readiness and academic resilience simultaneously were effective in determining the subjective well-being of students $(R=0.09, p<0.0$ I $)$
\end{abstract}

Keywords: subjective well-being, academic resilience, online learning readiness, pandemic COVID-I9.

Received 20 July 2021/Accepted 18 August 2021 @Author all rights reserved

\section{Introduction}

The COVID-19 pandemic has changed the world of education in various aspects, including the delivery of learning materials. The government of Indonesian has implemented online learning during the pandemic. Krsmanovic, Djuric, and Dmitrovic (20II) define online learning as a method to deliver learning material separated by time and space by utilizing communication technology. Online learning is not something new in education in Indonesia. For example, Universitas Terbuka has implemented it since 1984 (Hidayat, 2020).

Students who had attended school with conventional learning methods (before COVID-I9), 
undergoing an online learning process, made them face many challenges. Terada (2020) said that the learning process during the COVID-19 pandemic could reduce the level of students' wellbeing and lead to more cases among children and adolescents with complex challenges in learning. To be able to adapt and handle stress well, students need a healthy psychological condition (Proctor \& Linley, 20 I4). It means that students need to realize subjective well-being in undergoing the online learning process. However, for students who are undergoing online learning for the first time, this process poses challenges that can reduce the quality of their subjective well-being.

Previous studies (Sahu, 2020; Daniel, 2020; Chi, Becker, Yu, Willeit, Jiao, Huang, \& Veronese, 2020) have identified the impact of changes in learning methods on the psychological conditions of learners during a pandemic. Sahu (2020) found that the rapid increase in the number of positive cases of COVID-19 has created anxiety and a sense of uncertainty in students in China. This condition can increase stress in students. Then, Daniel (2020) confirmed that the conditions during the COVID-19 pandemic made students anxious because of the new teaching methods, the uncertainty about the exams, graduation, and learning outcomes.

Researchers have conducted a preliminary survey involving 30 private junior high school students in Lampung about their responses to online learning in the past month (July 2020). The results showed the students' feeling of bored (73.2\%), confused (65.9\%), tired (58.5\%), stress (5I.2\%), normal (34.1\%), anxious (31.7\%), sad (24.4\%), scared (24.4\%), enjoy (22\%), and happy (19.5\%). The reasons for their negative emotions include: (I) feeling confused about the material and decreased mastery of the material, (2) feeling bored because they cannot interact with teachers and friends directly, (3) experiencing stress and tiredness due to task burdens, and (4) feeling anxious about the assessment in which they are afraid the possibility of decreased and less objective score. The results of this survey illustrate that most students evaluate themselves to feel more negative emotions in the online score learning process. Self-evaluation of the emotional experiences experienced by individuals is a picture of the subjective well-being condition (Diener, 1999). More negative evaluations indicate that students experience low subjective well-being. Subjective well-being can be operationalized as self-appraisals of one's private behavior (thoughts and feelings) and public behavior (verbal and physical actions) that are deemed personally or socially desirable (Renshaw, 20I5). 
Maddux (2018) said that students' subjective well-being is a psychological condition that describes how students feel and think about what happens to them in life. Students are said to have a high level of subjective well-being if they feel satisfied with life and show positive emotional reactions or responses to each of their life experiences, and rarely feel unpleasant emotions such as sadness or anger (Diener, 1999). Tian, Zhao, and Huebner (2015) explained that subjective well-being in students is when students evaluate positive or negative emotions that are experienced specifically during the learning process, for example exciting, happy, relaxed, tired, annoyed, bored, and sad. In this study, researchers focused on students' subjective well-being on the affective aspects as researchers wanted to identify emotional experiences felt by students. During this pandemic, ideally, students complain a little, have the confidence to complete academic demands, and remain enthusiastic about learning.

Internal conditions (resilience) can affect the subjective well-being of students who undergo online learning. Renshaw and Arslan (2016) stated that positive psychological resources such as resilience can facilitate students to improve their subjective well-being and psychological health. Resilience is the individual's ability to cope with, through/undergo, and return to its original state after experiencing difficulties (Reivich \& Shatte, 2002). The students' resilience in the online learning process is referred to as academic resilience. Martin and Marsh (2003) define academic resilience as the ability to deal with setbacks, stress, or pressure effectively in an academic setting. Resilience is an asset that plays an important role in subjective well-being (Bartley, Schoon, Mitchell, \& Blane, 20I0).

A study by Yildirim and Arslan (2020) focusing on the impact of resilience on subjective wellbeing in 220 students in Turkey showed that resilience has a direct effect on psychological health and subjective well-being. Generally, students who have high resilience have healthier psychological conditions and lower levels of stress during activities during the COVID-19 pandemic (Barzilay, Moore, Greenberg, DiDomenico, Brown, White, \& Gur, 2020). Shaws (2020) states that resilience is a dynamic process of adapting and managing the difficulties that occur so that resilience can improve the quality of subjective well-being during this pandemic. Nashori and Saputro (2020) found that resilience is needed during the COVID-19 pandemic to maintain psychological well-being and to empower amid existing limitations. 
Besides resilience, during the online learning process, learning readiness can affect the students' subjective well-being (Joosten \& Cusatis, 2020). Online learning requires students and teachers to be skilled at using communication technology media in their activities. Both teachers and students must provide supporting devices and have the ability to operate them. Online learning readiness is a condition when students can undergo the online learning process, such as technical skills in using communications devices, communication skills, and the ability to interact with teachers and other students (Yu \& Richardson, 20I5). Online learning readiness is an attribute needed by students to undergo online learning, such as knowledge and skills in using learning applications (Joosten \& Cusatis, 2020). Gikas and Grant (2013) added that mobile devices support such as smartphones, tablets, or laptops is needed in online learning to access information anywhere and anytime. Students with online learning readiness usually have lower levels of stress and anxiety because they can overcome technical problems in learning (Korucu \& Alkan, 20 I I; Dai, Chai, Lin, Jong, Guo, \& Qin, 2020).

Based on the explanation above, the researcher assumes that academic resilience and online learning readiness affect the students' subjective well-being during the online learning process. Therefore, the issues or problems examined in this study are the latest situations that occur in society. Besides, the variables in this study were adjusted to the context of online learning during the COVID-19 pandemic. This study is expected to enrich the knowledge of psychology, especially in the field of educational psychology. The formulation of the problem in this study is 'do online learning readiness and academic resilience affects the students' subjective well-being?' The results of this study are expected to motivate future studies on the educational issue experienced by the community. The hypothesis in this study is online learning readiness and academic resilience affect students' subjective well-being.

\section{Method}

\section{Participants}

The study involved 200 participants (boys and girls, ages 13 to 16 years) from grades 7, 8, and 9 of a private junior high school in Central Lampung who are implementing online learning. This study used a quota sampling technique, which is a technique to determine a sample of a population that has certain characteristics to the desired quota (Supranto, 2000). The researcher 
referred to the sample size table as proposed by Krejcie and Morgan. If the population is 500 people with a significance level of $10 \%$, then the sample size is 176 . The data were collected by distributing questionnaires online. Information about informed consent was presented at the beginning of the questionnaires, so that respondent involvement was voluntary.

\section{Instruments}

This study used three research instruments: (a) a scale of positive and negative experience (SPANE). The SPANE scale was designed based on the subjective well-being theory proposed by Diener, Wirtz, Tov, Kim-Prieto, Choi, Oishi, and Biswas-Diener, (2009), with a Cronbach Alpha coefficient of 0.740 . The scale consisted of 12 items with 6 items for positive feelings and 6 items for negative feelings. Participants were asked to evaluate their experiences and feelings during the past one month. (b) academic resilience scale, based on the theory of Martin and Marsh (2006) with a Cronbach alpha value of 0.902 . The scale consisted of six items arranged based on aspects of academic resilience including confidence, control, composure, and commitment. (c) student's e-learning readiness questionnaire, based on the theory of Aydin and Tasci (2005) with a Cronbach alpha value of 0.798 . It consisted of 25 items including the skills in using computers/smartphones, understanding of online learning technology, readiness to receive learning materials through online learning, and attitudes towards ICT (Information and Communication Technology).

\section{Data Analysis}

The data were analyzed using multiple regression analysis techniques with the help of SPSS 20 software. The assumption tests were performed before testing the hypothesis including normality, linearity, multicollinearity, heteroscedasticity, and autocorrelation tests. After fulfilling the assumption test, data analysis was continued with hypothesis testing and effective contribution ( $R$ square). 


\section{Result}

Descriptive Statistics Results

The objectives of this study are to investigate the contributions of academic resilience and online learning readiness towards subjective well-being. Prior to that, this study will first disseminate the descriptive findings about these three (3) variables.

Table I

Subjective well-being categorization $(M=4 I$ and $S D=5.3)$

\begin{tabular}{ccccc}
\hline Variable & Value Range & Category & Total & Percentage \\
\hline \multirow{2}{*}{$\begin{array}{c}\text { Subjective well- } \\
\text { being }\end{array}$} & $36 \leq 36$ & Low & 56 & $28.0 \%$ \\
& $X>46$ & Moderate & III & $55.5 \%$ \\
\hline & High & 33 & $16.5 \%$ \\
\hline
\end{tabular}

In this study, the level of subjective well-being among students was mostly in the medium category with a total of I I I (55.5\%) students (see Table I).

Table 2

Online learning readiness categorization $(M=90, S D=1 / .6)$

\begin{tabular}{ccccc}
\hline Variable & Value Range & Category & Total & Percentage \\
\hline \multirow{2}{*}{$\begin{array}{c}\text { Online learning } \\
\text { readiness }\end{array}$} & $X<78$ & Low & 36 & $18.0 \%$ \\
& $78 \leq x \leq 102$ & Moderate & 143 & $71.5 \%$ \\
& $X>102$ & High & 21 & $10.5 \%$ \\
\hline & Total & & 200 & $100.0 \%$ \\
\hline
\end{tabular}

The level of online learning readiness of the students was mostly in the medium category with a total of I43 (7I.5\%) students (see Table 2).

Table 3

Academic resilience categorization $(M=3 /$ and $S D=3.6)$

\begin{tabular}{ccccc}
\hline Variable & Value Range & Category & Total & Percentage \\
\hline \multirow{2}{*}{ Academic } & $X<27$ & Low & 30 & $15.0 \%$ \\
resilience & $27 \leq X \leq 35$ & Moderate & 81 & $40.5 \%$ \\
& $X>35$ & High & 89 & $44.5 \%$ \\
\hline & Total & & 200 & $100.0 \%$ \\
\hline
\end{tabular}

The level of resilience of the students was mostly in the medium and high categories with 8I (40.5\%) and 89 (44.5\%) students respectively (see Table 3). 


\section{Normality test}

The normality test used the Kolmogorov Smirnov Test. Table 4 shows that the significance value of students' subjective well-being variable is $0.096(p>0.05)$ and the online learning readiness variable is 0.200 ( $p 0.05$ indicates that the data distribution is normal. The academic resilience variable obtained a significance value of $0.001(p<0.05)$ meaning that the data distribution is not normal.

Table 4

Normality test results

\begin{tabular}{ccc}
\hline Variable & $P($ significance value $)$ & Data Distribution \\
\hline Subjective well-being & $0.096(p>0.05)$ & normal \\
Online learning readiness & $0.200(p>0.05)$ & normal \\
Academic resilience & $0.001(p<0.05)$ & not normal \\
\hline
\end{tabular}

\section{Linearity Test}

Linearity test to determine the linear relationship between variables used the test for linearity. The online learning readiness and subjective well-being variables showed a significance value of linearity of $0.001(p<0.05)$. It indicates that there is a significant linear relationship between the online learning readiness variable $(X I)$, academic resilience variable $(X 2)$, and subjective wellbeing variable $(Y)$.

Table 5 .

Linearity test results

\begin{tabular}{cccc}
\hline Variable & $F$ & $p($ significance value $)$ & Status \\
\hline $\begin{array}{c}\text { Subjective well-being } * \\
\text { Online learning readiness } \\
\text { Subjective well-being } * \\
\text { Academic resilience }\end{array}$ & 7.735 & $0.001(\mathrm{p}<0.05)$ & Linier \\
\hline
\end{tabular}

\section{Multicollinearity Test}

The multicollinearity test table above shows a tolerance value of $0.799(>0.1)$ and a VIF value of I.252 $(<10)$ for both variables. Therefore, it can be concluded that there is no multicollinearity in the data. 
Table 6.

Multicollinearity test results

\begin{tabular}{cccc}
\hline Variable & Tolerance & VIF & Status \\
\hline Online learning readiness & 0.799 & $\mathrm{I} .252$ & Multicollinearity not occur \\
Academic resilience & 0.799 & $\mathrm{I} .252$ & Multicollinearity not occur \\
\hline
\end{tabular}

\section{Heteroscedasticity Test}

Based on Table 7, the significance values of independent variables of academic resilience and online learning readiness are 0.005 (p 0.05 respectively. It means that for $>5 \%$, there is no heteroscedasticity in the data.

Table 7.

Heteroscedasticity test results

\begin{tabular}{ccc}
\hline Variable & $P($ significance value $)$ & Status \\
\hline Online learning readiness & $0.005(p<0,05)$ & Heteroscedasticity not occur \\
Academic resilience & $0.097(p<0,05)$ & Heteroscedasticity not occur \\
\hline
\end{tabular}

\section{Autocorrelation Test}

Based on Table 8, the significance value is 0.321 ( $>0.05)$. It means that for $>5 \%$, the data does not show autocorrelation problems. Some assumption test results indicate that the data can be continued for hypothesis testing through multiple regression models.

Table 8.

Autocorrelation test results

\begin{tabular}{lcl}
\hline Runs & $Z$ & Significance \\
\cline { 2 - 3 } Test & 0.801 & 0.321 \\
\end{tabular}

The relationship between online learning readiness and academic resilience with the students' subjective well-being

The correlation coefficient of the online learning readiness variable with the students' subjective well-being is 0.224 with a significance level of lower than 0.01 . These results indicate that there is a significant positive relationship between online learning readiness and students' subjective well- 
being. Moreover, the correlation coefficient between the academic resilience and the students' subjective well-being is 0.274 with a significance level of lower than 0.01 . It shows that there is a significant positive relationship between academic resilience and students' subjective well-being.

Table 9.

Correlation test results

\begin{tabular}{lccc}
\hline & $\begin{array}{c}\text { Online learning } \\
\text { readiness }\end{array}$ & $\begin{array}{c}\text { Academic } \\
\text { resilience }\end{array}$ & Subjective well-being \\
\hline online learning readiness & $\mathrm{I}$ & & \\
academic resilience & $0.488^{*}$ & $\mathrm{I}$ & \\
subjective well-being & $0.224^{*}$ & $0.274^{*}$ & $\mathrm{I}$ \\
\hline
\end{tabular}

\section{Hypothesis testing}

Results of the multiple linear regression indicated that there was a collective significant effect between online learning readiness, academic resilience, and students' subjective well-being ( $F(9$, $\left.506)=20.82, \mathrm{P}<.00 \mathrm{I}, \mathrm{R}^{2}=.088\right)$. It means that the hypothesis is accepted. Online learning readiness and academic resilience together can predict the students' subjective well-being in the online learning process.

Table 10.

Hypothesis test results

\begin{tabular}{cccc}
\hline Model & $F$ & Significance & R Square $\left(R^{2}\right)$ \\
\hline Regression & 9.506 & 0.000 & 0.088 \\
\hline
\end{tabular}

Table II.

Hypothesis test results

\begin{tabular}{lccc}
\hline \multicolumn{1}{c}{ Variables } & $F$ & Significance & R square $\left(R^{2}\right)$ \\
\hline online learning readiness & $I 0.50 I$ & $0.00 I(p<0.01)$ & 0.050 \\
academic resilience & 16.081 & $0.000(p<0.01)$ & 0.075 \\
\hline
\end{tabular}

Partially, online learning readiness affects the students' subjective well-being in online learning. The $R^{2}$ value of 0.050 indicates that the effective contribution of the online learning readiness variable 
to subjective well-being is $5 \%$. Meanwhile, the academic resilience variable obtained an $\mathrm{F}$ value of $16.08 \mathrm{I}$ and a significance value of $0.000(\mathrm{p}<0.0 \mathrm{I})$. It shows that academic resilience can affect the students' subjective well-being in online learning. The effective contribution of the academic resilience variable to the students' subjective well-being based on the $R^{2}$ value of 0.075 shows that the effective contribution is $7.5 \%$.

\section{Discussion}

The results of this study indicated that online learning readiness and academic resilience can affect the subjective well-being of junior high school students. Simultaneously, online learning readiness and academic resilience contribute $8.8 \%$ to the subjective wellbeing of students. This finding strengthens previous studies that students with high online learning readiness and academic resilience usually have better subjective well-being (Bartley, Schoon, Mitchell, \& Blane, 20I0; Amelasasih, Aditama, \& Wijaya, 2019; Yildirim \& Arslan, 2020; Barzilay, Moore, Greenberg, DiDomenico, Brown, White, \& Gur, 2020; Joosten \& Cusatis, 2020; Eva, Parameitha, Farah, \& Nurfitriana, 2020; Wei \& Chou, 2020).

In this study, the effective contribution of online learning readiness and academic resilience is classified as low. It can be caused by other factors affecting the subjective well-being of students. The factors include the ability to adapt, the ability to cope with stress, self-esteem, and religiosity as internal factors (Diponegoro, 2006; Maslihah, 2017; Ikromi, Diponegoro, \& Tentama, 2019). The external factors are the social support received by students, family conditions, and the environment (Hooghe \& Vanhoutte, 20II; Ikromi, Diponegoro, \& Tentama, 2019). However, the two independent variables in this study can still affect students' subjective well-being. It means that online learning readiness and academic resilience still need to be considered and improved.

Based on the results of the current study, online learning readiness can predict subjective wellbeing $(R=0.224, P<0.01)$. A positive correlation coefficient $(R=0.224)$ indicates that the higher the level of online learning readiness, the better the subjective well-being of students during online learning. These findings enrich the research and support the explanation that online learning readiness is important to improve the subjective well-being of students who are undergoing an online learning process. 
In this study, students studied online using various online platforms, such as Google classroom, Zoom meeting, Youtube, Whatsapp, Quizizz, Google meet, and additional applications such as Google form or Line. A total of $71.5 \%$ of students out of 200 students have a medium category of online learning readiness. Considering the varied types of online applications or platforms used in learning, students need to improve their online learning readiness. In line with the research of Dai, Chai, Lin, Jong, Guo, and Qin (2020), students need to improve their skills in using technology as a learning medium because students who are more prepared and skilled will learn better, be more productive, and have a positive feeling.

Some studies (Korucu \& Alkan, 20II; Gikas and Grant, 2013; Krsmanovic, Djuric \& Dmitrovic, 201 I; Joosten \& Cusatis, 2020) shows that students who have the knowledge and skills in using online learning support tools will be able to overcome sources of stress and anxiety so that they can learn well. The student's readiness for online learning, according to Hung, Chou, Chen, and Own (2010), covers (a) independent learning skills, (b) learning motivation, (c) self-efficacy using the internet, (d) ability to self-control, and (e) self-efficacy to communicate online.

Furthermore, this study confirmed that the academic resilience variable affects the subjective wellbeing of students $(r=0.274, p<0.0 I)$. A positive correlation coefficient indicates that the higher the level of academic resilience, the better the subjective welfare of students undergoing online learning. In line with research conducted by Martin and Marsh (2003), academic resilience is an ability that can make students face stress or pressure in academics. Academic resilience is an internal attribute that has been proven effective in improving the subjective well-being of students during the COVID-19 pandemic (Barzilay, Moore, Greenberg, DiDomenico, Brown, White, \& Gur, 2020). Students who have a high level of academic resilience can turn stressful events into opportunities to develop and to rise from difficult times (Santhosh \& James, 2013).

This study is in line with previous studies that have reported a positive relationship between academic resilience and the subjective well-being of students. Yıldırım and Tanrıverdi (2020) found a positive correlation between academic resilience and subjective well-being $(r=0.30, p<0.0 \mathrm{I})$. The results of this study explain that students who have high resilience will be able to bounce back from stressful situations. They are likely to be happier, more satisfied, and prosperous in life. Further, Yildirim and Arslan (2020) see a positive relationship $(r=0.58, p<0.01)$ between academic 
resilience and the subjective well-being of students who are undergoing learning during the COVID-19 pandemic.

Other studies conducted by Kirmani, Sharma, Anas, and Sanam (20I5) examined the relationship between expectations, resilience, and the subjective well-being of adolescents. The results of the study indicated that there is a positive correlation between resilience and subjective well-being ( $r$ $=0.42, \mathrm{p}$ p <0.0I). Then, Amelasasih, Aditama, and Wijaya (2019) found that there is a significant positive correlation between academic resilience and subjective well-being $(r=0.73, P<0.05)$. It means that students who have good academic resilience also have high subjective well-being. Furthermore, Eva, Parameitha, Farah, and Nurfitriana (2020) concluded that students with high levels of academic resilience tend to have a high level of subjective well-being as they can regulate their emotions well, control internal stress, and adapt to online learning during the COVID-I9 pandemic, which also leads to improved mental health.

Generally, every study has weaknesses or limitations. The limitation of this study lies in the data collection process which was done online. Researchers are not sure whether the students understand the instructions and the intent of each item well. Researchers cannot control the process when students fill in the scale. Apart from the process, the results indicate that the role or contribution of the independent variable to the dependent variable is low.

\section{Conclusion}

The results of the research and discussion above support the statement that online learning readiness and academic resilience together can affect the subjective well-being of junior high school students who are undergoing online learning. Partially, each independent variable also influences the dependent variable. In this study, academic resilience has a more dominant influence than online learning readiness. This research implies that maintaining subjective wellbeing during the online learning process is important. The COVID-19 pandemic causes various negative emotional reactions. Therefore, students need to have good academic resilience to rise from difficult times and overcome negative feelings to improve the quality of their subjective wellbeing. Besides, students who are undergoing online learning during a pandemic need to improve their learning readiness including knowledge and skills in using online technology and applications 
because online learning readiness can help students to minimize sources of stress and anxiety caused by the online learning process. Therefore, the subjective well-being of students can be maintained. Future researchers are expected to examine high school and vocational school students in different cities.

\section{References}

Amelasasih, P., Aditama, S., \& Wijaya, M. R. (2019). Resiliensi akademik dan subjective well-being pada mahasiswa. Proceeding National Conference Psikologi UMG. I(I), I6I-I67

Aydın, C. H., \&Tasci, D. (2005). Measuring readiness for e-learning: Reflections from an emerging country. Journal of Educational Technology \& Society, 8(4), 244-257.

Bartley M., Schoon I., Mitchell R., Blane D. (2010) Resilience as an asset for healthy development. In: Morgan A., Davies M., Ziglio E. (edcxs) Health Assets in a Global Context. Springer. I0I-I I5. https://doi.org/10.1007/978-I- 4419-592I-8_6

Barzilay, R., Moore, T.M., Greenberg, D.M. et al. (2020). Resilience, COVID-19 related stress, anxiety, and depression during the pandemic in a large population enriched for healthcare providers. Translational Psychiatry, 10, 291. https://doi.org/10.1038/ s41398-020-00982-4

Chi, X., Becker, B., Yu, Q., Willeit, P., Jiao, C., Huang, L., \& Veronese, N. (2020). Prevalence and psychosocial correlates of mental health outcomes among chinese college students during the coronavirus disease (COVID-19) Pandemic. Frontiers in Psychiatry, II, 803. https://doi.org// 0.3389/fpsyt.2020.00803

Dai, Y., Chai, C. S., Lin, P. Y., Jong, M. S. Y., Guo, Y., \& Qin, J. (2020). Promoting students' wellbeing by developing their readiness for the artificial intelligence age. Sustainability, $12(16)$, 6597. https://doi.org//0.3390/sul2166597

Daniel, S. J. (2020). Education and the COVID-19 pandemic. Prospects, I-6. https://doi.org/ $\underline{|0.1007 / \mathrm{s}||| 25-020-09464-3}$

Diener, E., Oishi, S., \& Lucas, R. L. (2003). Personality, culture, and subjective well-being: Emotional and cognitive evaluations of life. Annual Review of Psychology, 54(I), 403425.https://doi.org/10.1146/annurev.psych.54.101601.145056.

Diener, E., Wirtz, D., Tov, W., Kim-Prieto, C., Choi. D., Oishi, S., \& Biswas-Diener, R. (2009). New measures of well-being: Flourishing and positive and negative feelings. Social Indicators Research, 39, 247-266. https://doi.org//0.1007/978-90-48I-2354-4_12

Diponegoro, A. M. (2006). Peran stress management terhadap kesejahteraan subjektif. Humanitas: Jurnal Psikologi Indonesia, 3(2), 22-35 
Eva, N., Parameitha, D. D., Farah, F. A. M., \& Nurfitriana, F. (2020). Academic resilience and subjective well-being amongst college students using online learning during the COVID-I9 Pandemic. KnE Social Sciences, 202-2I4.

Gikas, J., \& Grant, M. M. (2013). Mobile computing devices in higher education: Student perspectives on learning with cellphones, smartphones \& social media. The Internet and Higher Education, 19, 18-26. https://doi.org/10.1016/j.iheduc.2013.06.002

Hidayat, M. I. (2020). Google classroom sebagai alternative pelaksanaan pembelajaran daring dalam masa pandemic COVID-19. Minda Mahasiswa Indonesia: Kenali Industri 4.0 Hadapi COVID-19, 23.

Hooghe, M. \& Vanhoutte, B., (20II). Subjective well-being and social capital in Belgian communities: the impact of community characteristics on subjective well-being in Belgium. Social Indicators Research, 100, 17-36. https://doi.org/10.1007/ s I 1205-010-9600-0

Hung, M. L., Chou, C., Chen, C. H., \& Own, Z. Y. (2010). Learner readiness for online learning: Scale development and student perceptions. Computers \& Education, 55(3), 1080-1090. https://doi.org/10.1016/j.compedu.2010.05.004

Ikromi, Z. A., Diponegoro, A. M., \& Tentama, F. (2019). Faktor psikologis yang mempengaruhi subjective well-being pada remaja yang tinggal di pondok pesantren. In Prosiding Seminar Nasional Magister Psikologi Universitas Ahmad Dahlan. 4I2-420.

Joosten, T., \& Cusatis, R. (2020). Online learning readiness. American Journal of Distance Education, I14. https://doi.org//0.1080/08923647.2020.1726/67

Korucu, A. T., \& Alkan, A. (20I I). Differences between m-learning (mobile learning) and e-learning, basic terminology, and usage of m-learning in education. Procedia-Social and Behavioral Sciences, 15, 1925-1930. https://doi.org/10.1016/j.sbspro. 2011.04.029

Krsmanovic, M., Djuric, M., \& Dmitrovic, V. (20II). A survey of student satisfaction with distance learning at faculty of organizational sciences, University of Belgrade. In International Conference on Virtual and Networked Organizations, Emergent Technologies, and Tools (pp. IIII 17). Springer. https://doi.org//0.1007/978-3-642-3/800-9_12

Maddux, J. E. (2018). Subjective well-being and life satisfaction: An introduction to conceptions, theories, and measures. In J. E. Maddux (Ed.), Frontiers of social psychology. Subjective WellBeing and Life Satisfaction (p. 3-3I).

Martin, A. J., \& Marsh, H. W. (2006). Academic resilience and its psychological and educational correlates: A construct validity approach. Psychology in the Schools, 43(3), 267-28I. https://doi.org/10.1002/pits.20149

Maslihah, S. (2017). Faktor yang mempengaruhi kesejahteraan subjektif anak didik Lembaga Pembinaan Khusus Anak. Jurnal Psikologi Insight, I(I), 82-94.

Nashori, F. \& Saputro, I. (2020). Psikologi resiliensi. Yogyakarta: Universitas Islam Indonesia 
Proctor, C., \& Linley, P. A. (20|4). Life satisfaction in youth. In G. A. Fava \& C. Ruini (Eds.), Increasing psychological well-being in clinical and educational settings (Cross-cultural advancements in positive psychology 8) (pp. 199-215). Springer. https://doi.org/10.1007/978-94-017-8669$\underline{0} 13$

Renshaw, T. L., Long, A. C. J., \& Cook, C. R. (20I5). Assessing adolescents' positive psychological functioning at school: Development and validation of the student subjective wellbeing questionnaire. School Psychology Quarterly, 30(4), 534-552. https://doi.org//0.1037/ spq0000088

Renshaw, T. L., \& Arslan, G. (20I6). Psychometric properties of the student subjective wellbeing questionnaire with Turkish adolescents: A generalizability study. Canadian journal of school psychology, 3 I (2), I39-I5 I. https://doi.org/ /0.II77/08295735I6634644

Reivich, K., \& Shatté, A. (2002). The resilience factor: 7 essential skills for overcoming life's inevitable obstacles. Broadway books.

Sahu, P. (2020). Closure of universities due to coronavirus disease 2019 (COVID-19): Impact on education and mental health of students and academic staff. Cureus, 12(4). https://doi.org/10.7759/cureus.754I

Santhosh, K. R., \& James, J. (20I3). The effect of resilience on burnout among the blue collared employees in metal factories. EXCEL International Journal of Multidisciplinary Management Studies, 3(6), 48-55.

Shaw, S. C. (2020). Hopelessness, helplessness, and resilience: The importance of safeguarding our trainees' mental wellbeing during the COVID-I9 pandemic. Nurse Education in Practice, 44, 102780. https://doi.org/10.1016/j.nepr.2020.102780

Supranto, J. (2000). Teknik sampling untuk survei dan eksperimen. Penerbit PT RinekaCipta, Jakarta

Terada, Y. (2020). COVID-19's impact on students' academic and mental well-being. Diunduhdarihttps://www.edutopia.org/article/COVID-19s-impact-students-academic-andmental-well-being

Tian, L., Zhao, J., \& Huebner, E. S. (2015). School-related social support and subjective well-being in school among adolescents: The role of self-system factors. Journal of Adolescence, 45, 138 148. https://doi.org//0.1016/j.adolescence.2015.09.003

Wei, H., \& Chou, C. (2020). Online learning performance and satisfaction: Do perceptions and readiness matter? Distance $\quad$ Education, 4I(I), 48-69. https://doi.org/10.1080/01587919.2020.1724768

Yildirim, M., \& Arslan, G. (2020). Exploring the associations between resilience, dispositional hope, subjective well-being, and psychological health among adults during the early stage of COVID-19. Current Psychology. I-27. https://doi.org/I0.1007/s I2144- 020-0I I77-2 
Yıldırım, M., \& Tanrıverdi, F. Ç. (2020). Social support, resilience, and subjective well-being in college students. Journal of Positive School Psychology, 4(3), 356-367.

Yu, T., \& Richardson, J. C. (20I5). An exploratory factor analysis and reliability analysis of the student online learning readiness (SOLR) instrument. Online Learning, 19(5), I20-I4I. 